\title{
Stabilisation of diaphyseal fractures of both bones forearm with limited contact dynamic compression or locked compression plate: comparison of clinical outcomes
}

\author{
S. P. S. Gill*, Ankit Mittal, Manish Raj, Pulkesh Singh, Sunil Kumar, Dinesh Kumar
}

Department of Orthopaedics, Uttar Pradesh University of Medical Science, Saifai, Etawah, Uttar Pradesh, India

Received: 28 March 2017

Accepted: 19 April 2017

*Correspondence:

Dr. SPS Gill,

E-mail: simmygill@gmail.com

Copyright: () the author(s), publisher and licensee Medip Academy. This is an open-access article distributed under the terms of the Creative Commons Attribution Non-Commercial License, which permits unrestricted non-commercial use, distribution, and reproduction in any medium, provided the original work is properly cited.

\begin{abstract}
Background: The inception of Locking Compression Plate (LCP) has revolutionized fracture management. With their dramatic success for articular fractures, there is a speculation that they might be more appropriate for diaphyseal fractures as well.

Methods: In this randomized prospective cohort study, 56 patients with diaphyseal fractures involving both bones of forearm were segregated into two groups based on internal fixation with Limited contact dynamic compression plate $(\mathrm{LC}-\mathrm{DCP})(\mathrm{n}=28)$ or with Locking compression plate $(\mathrm{LCP})(\mathrm{n}=26)$. Clinical and radiological parameters were studied and functional evaluation was done with Disabilities of arm, shoulder, and hand (DASH) score.

Results: Andersons' criteria was employed to categorize the functional results. The mean duration of surgery and time to union were discovered to be less in favor of LCP group although statistically insignificant. No significant differences in two groups with respect to the functional evaluation (range of movement, Andersons' criteria and DASH score) and complications could be discerned. No incidence of refracture or synostosis was encountered in any of the group.

Conclusions: Although LCP is an effective treatment alternative and may have a subtle edge over LC-DCP in the management of these fractures, their supremacy could not be certified. We deduce that surgical planning and expertise rather than the choice of implant are more pivotal for outstanding results.
\end{abstract}

Keywords: Limited contact dynamic compression plate (LC-DCP), Locking compression plate (LCP), Fractures both bones of forearm

\section{INTRODUCTION}

Forearm plays a cardinal role in the function of upper extremity. Fractures involving both bones of forearm have been acknowledged as articular fractures as even minor aberration in the spatial orientation of radius and ulna can appreciably debilitate the performance of hand. ${ }^{1-}$ ${ }^{3}$ To acquire adequate range of pronation and supination, reclamation of length, apposition, axial and rotational alignment is paramount. Deforming muscular forces make union complexities more plausible. ${ }^{4}$ Although open reduction and internal fixation with plate is commonly accustomed as a treatment of choice, the most efficacious implant remains unsettled. ${ }^{5}$ Through ages, compression has been adjudged as an indispensible tool to achieve rigid internal fixation. ${ }^{6-8}$ With conventional plating, the friction at plate bone interface lends stability at the expense of periosteal perfusion. ${ }^{9,10}$ Past few decades have introduced new implants in an effort towards biological plating which preserve vascularization more competently allowing early mobilization with a capably stable fixation. ${ }^{11}$ 
In 1991, was popularized the limited contact dynamic compression plate (LCDCP), an amelioration over the dynamic compression plate (DCP), which claimed to reduce the bone plate area by $50 \%$, thereby decreasing the plate interference with the cortical perfusion and thus diminishing cortical porosis. ${ }^{12}$ Point contact fixator (PC Fix), was the first implant that did not confide on the plate bone interface for stability as it further diminished the contact area to mere point contacts of the plate with the bone. ${ }^{9}$

Then originated the concept of locking compression plates (LCP), which incorporated the features of LCDCP and PC-Fix and had the provision of a combined hole which can entertain an unlocked compression screw or a locking screw. ${ }^{9}$ They can aid biological fixation by being placed in a bridge plate technique in a comminuted fractures and have been asserted to allow rapid bone healing thus abbreviating union complications. ${ }^{10,13}$

The current study was organized to assess the supremacy of LCP over LCDCP if any, in the management of diaphyseal fractures both bones forearm.

\section{METHODS}

A total of 54 patients sustaining fractures of shaft of both bones of forearm between January 2012 to December 2014 satiating the inclusion and exclusion criteria were incorporated in this institutional review board approved randomized prospective study. ORIF with either LCDCP (Group LC-DCP; 28 patients) or LCP (Group LCP; 26 patients) was performed on the basis of block randomization with the random number table. Radiological and functional outcomes were assessed and compared. The protocol of this study was approved by the relevant ethical committee of our institution. All subjects gave full and informed consent to participate in the study. AO ASIF classification was utilized to classify them and number of patients in each subgroup.

\section{Inclusion criteria}

Inclusion criteria were age 18-60 years, diaphyseal both bone forearm fracture, all Close fractures and open fractures up to Gustilo grade 1, polytrauma without any significant ipsilateral upper limb fractures.

\section{Exclusion criteria}

Exclusion criteria were significant concomitant ipsilateral upper extremity trauma, preoperative significant functional loss or comorbidity in ipsilateral upper extremity, pathological fractures, patients not fit for surgery due to other medical conditions.

Surgery was performed within 2-12 days of admission. Open fractures were debrided and splinted on admission and taken up for surgery after ensuring a healthy wound.

\section{Operative procedure}

The surgeries were performed by the same team of orthopaedic surgeons without ascribing any preference to any implant. All surgeries were accomplished under general anaesthesia or regional block. A pneumatic tourniquet was used in all the surgeries and $1 \mathrm{~g}$ of $3^{\text {rd }}$ generation injectable cephalosporin was administered prophylactically. Duration of surgery was recorded in all cases to draw a comparison of the means between the groups.

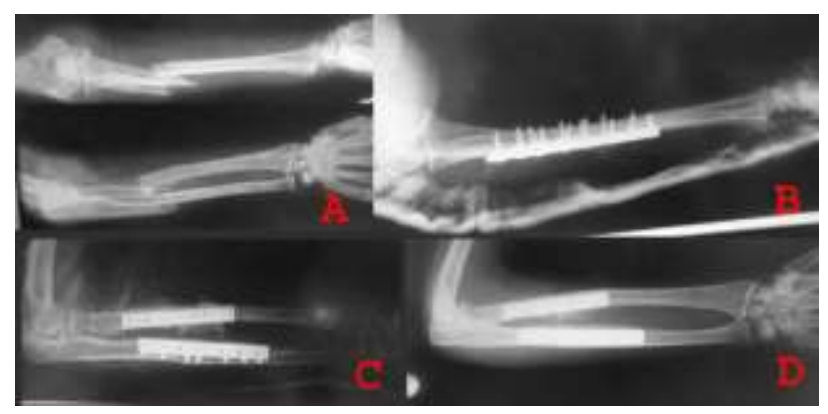

Figure 1: Case 1- DCP Forearm. A) Case 1preoperative radiograph of fracture both bone forearm, B) Case 1- post operative radiograph both bone fracture managed by DCP plating- lateral view,

C) Case 1- Post operative radiograph both bone fracture managed by DCP plating- AP view, D) follow up radiograph with fracture union after 12 weeks.

Surgical techniques as dictated by the AO/ASIF group were exercised. A volar henry approach was utilized to fix the fractures of radius at any level. Ulna was exposed through an incision over its subcutaneous border and its dorsal surface was plated. Care was taken to avert periosteal stripping. The bone with a transverse fractures or a less comminuted fractures was fixed first. Fixation was carried out with a $3.5 \mathrm{~mm}$ LCDCP OR LCP with a minimum of 3 Screws (6 cortices) on either side of fractures. In case of transverse or oblique fractures, compression was achieved by using 2 screws in compression mode (eccentric) on either side of fractures site and lag screw was used wherever necessary with either implant. In comminuted fractures where LCP was used, bridging technique was implemented and all screws were inserted in locking mode after attaining length and alignment.

Before closure, tourniquet was released and haemostasis accomplished .A splint was applied for 2 weeks and wrist and elbow exercises were commenced immediately.

Patients were discharged 3-7 days following surgery and were followed in office at 2 weeks for suture removal, then 4 weeks, then monthly till minimum 6 months or fractures union and 3 monthly thereafter. Clinicoradiological examination was accomplished at each follow up. AP and Lateral views of fracture were obtained. Osseous healing was designated radio logically 
as the presence of at least 3 of the 4 cortices with bridging callus formation and crossing trabeculae in AP and lateral radiographs. Absence of pain and tenderness at fracture site dictated the achievement of clinical healing. The quality of fractures reduction was assessed with the criteria of Leung and Chow. ${ }^{5}$ According to this definition, anatomic reduction refers to full reduction in which the complete length and alignment are achieved, and the compression of the butterfly fragments is provided by means of the lag screws. Non anatomic reduction refers to an incomplete anatomic reduction in which the length and alignment of the fracture fragments are achieved.
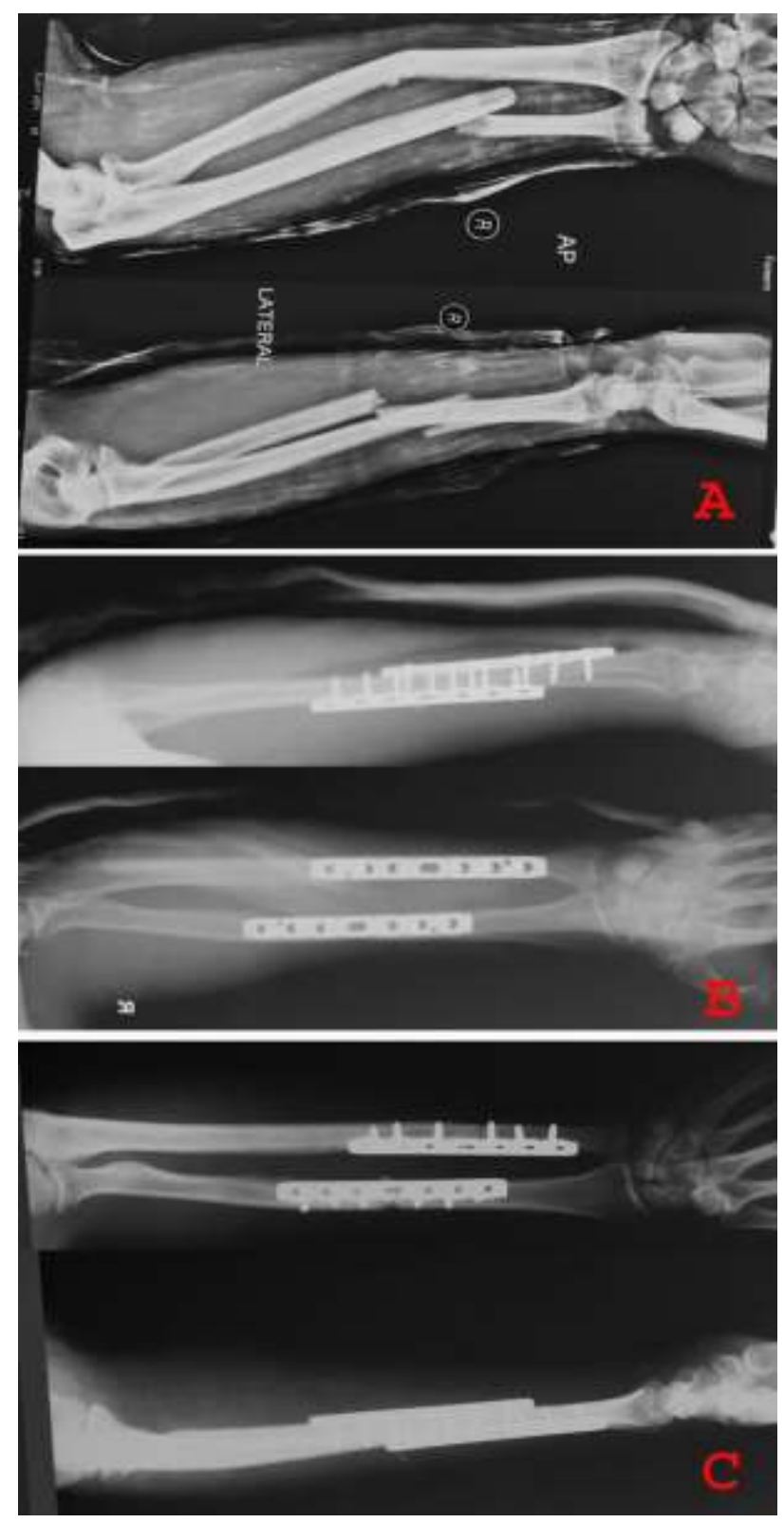

Figure 2: Case 2- LCP forearm. A) Case 2preoperative radiograph of fracture both bone forearm, B) Case 2- postoperative radiograph both bone fracture managed by LCP plating-AP \& lateral view, C) Case 2-follow up radiograph with fracture union after 12 weeks.

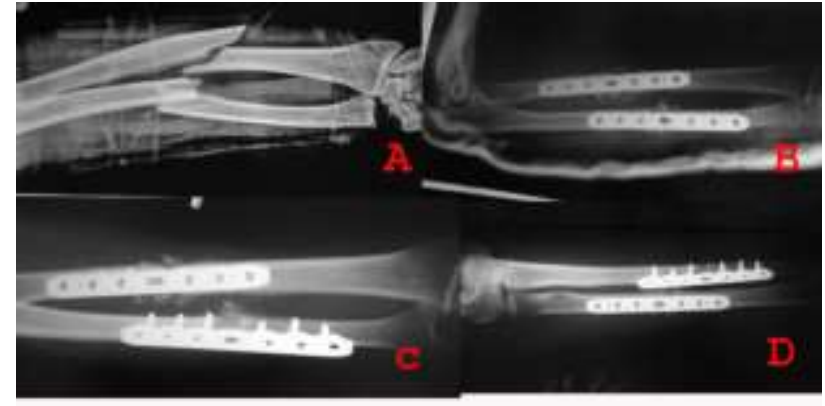

Figure 3: Case 3- LCP Forearm. A) Case 3preoperative radiograph of fracture both bone forearm, B) Case 3- post operative radiograph both bone fracture managed by LCP plating, C) Case 3follow up radiograph after 6 weeks, D) Case 3-follow up radiograph with fracture union after 12 weeks.
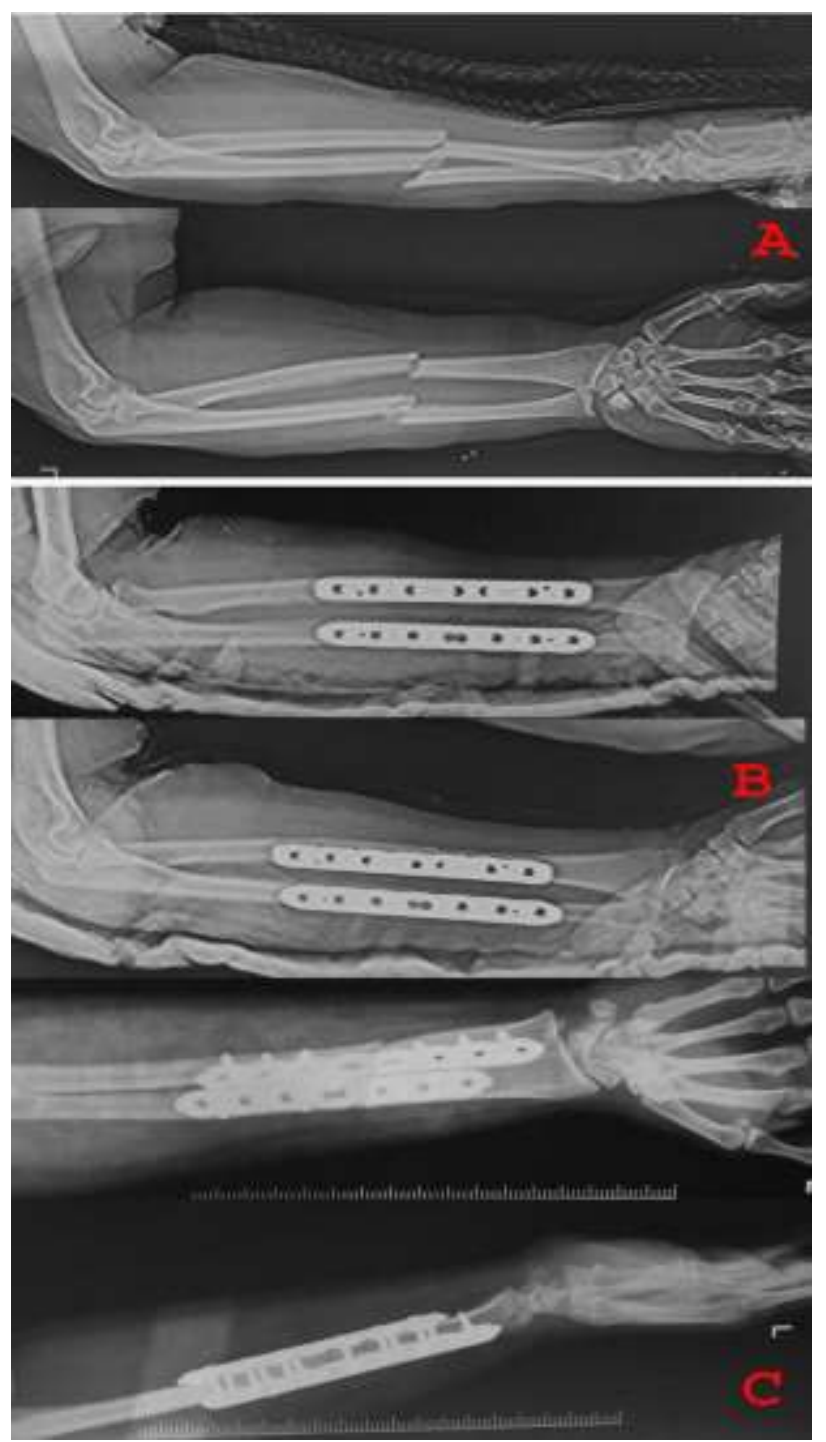

Figure 4: Case 4- LCP Forearm. A) Case 4preoperative radiograph of fracture both bone forearm, B) Case 4- postoperative radiograph both bone fracture managed by LCP plating-AP \& Lateral view, C) Case 4-follow up radiograph with fracture union after 12 weeks. 

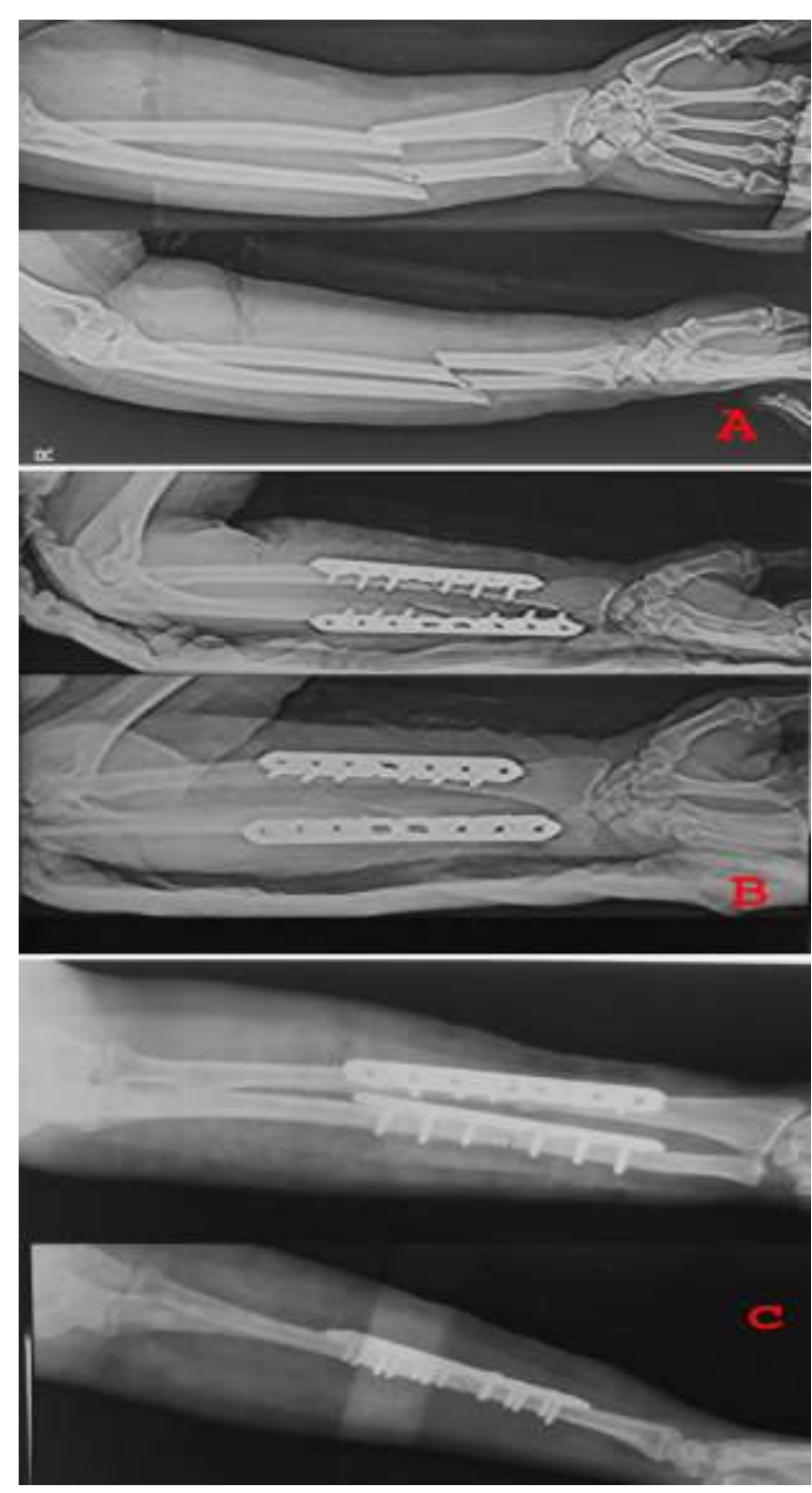

Figure 5: Case 5- LCP forearm.

A) Case 5- preoperative radiograph of fracture both bone forearm, B) Case 5- post operative radiograph both bone fracture managed by LCP plating-AP \& lateral view, C) Case 5-follow up radiograph with fracture union after 12 weeks.

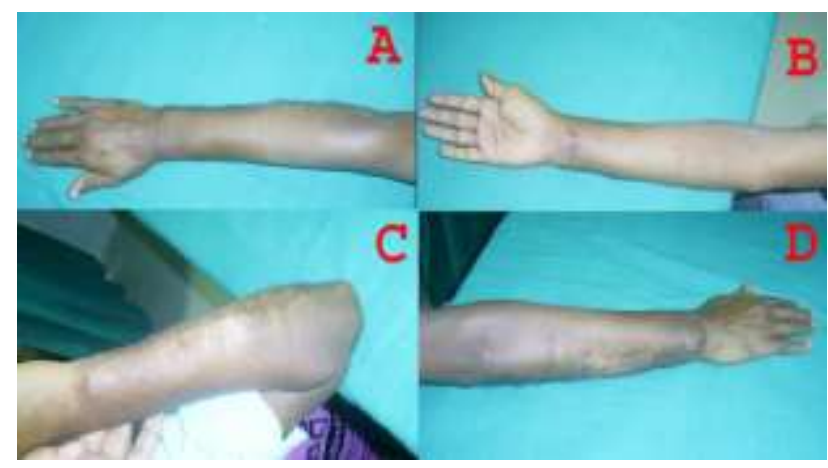

Figure 6: Clinical results- DCP forearm.

A) forearm pronation, B) forearm supination, C) elbow flexion, D) elbow extension.

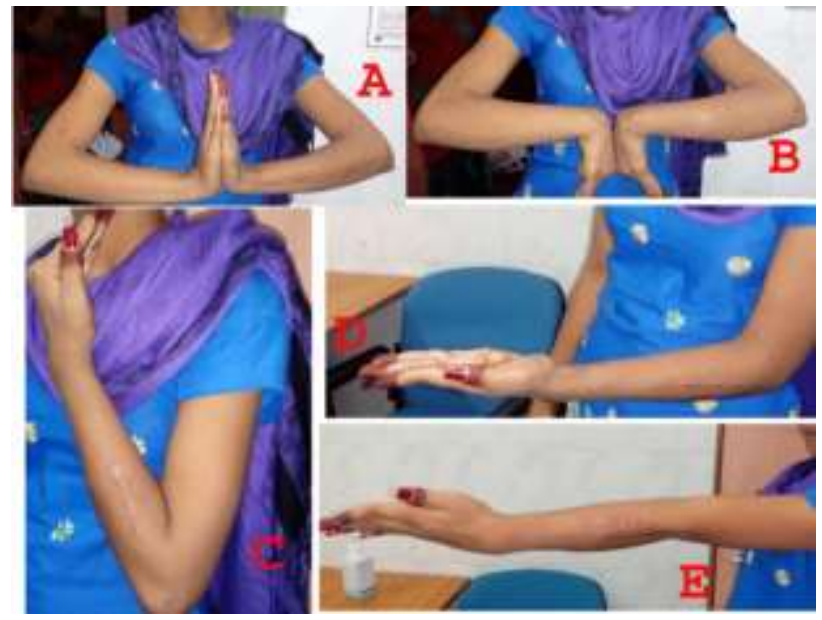

Figure 7: Clinical results- LCP forearm. A) Wrist extension and forearm pronation, B) Wrist flexion and forearm pronation, C) Elbow flexion and supination, D) Forearm supination, E) Elbow extension.

The assessment of bony union based on the criteria of Anderson. ${ }^{6}$ Fractures that healed in less than six months were classified as unions; those which required more than six months to unite but without any additional operative procedure were categorized as delayed unions; and those which failed to unite without further operative intervention were distinguished as non-unions. The functional outcome was assessed using the criteria of Anderson. 6

Patients were assessed for complications related to wound healing, infection, neurovascular injuries, nonunion, loss of reduction, synostosis or refracture.

Disabilities of the Arm, Shoulder and Hand (DASH) questionnaire was used to assess patient rated outcomes. ${ }^{14}$ It comprised of a 30-item questionnaire designed to assess the function and symptoms of patients with disorders of the upper limb. Calculations beginning at one year follow up were done and repeated at every further follow up. Latest values were used to compare the groups.

One way ANOVA test was used to analyze the difference of means for different parameters. The test was referenced for a two-tailed $\mathrm{p}$ value and $95 \%$ confidence interval was constructed around sensitivity proportion using normal approximation method. The Fischers' exact test was used for the comparison of paired categorical variables. SPSS software was used to perform statistical analyses. A value of $<0.05$ was considered statistically significant.

\section{RESULTS}

The functional outcome was assessed using the criteria of Anderson in Table 1. ${ }^{6}$ The demographic profile was reflected in Table 2 . 
Table 1: Anderson et al, criteria for assessment of functional outcome.

\begin{tabular}{|llll|}
\hline Result & Union & Flexion and extension at wrist joint & Supination and Pronation \\
\hline Excellent & Present & $<10$ Deg loss & $<25 \%$ loss \\
\hline Satisfactory & Present & $<20$ loss & $<50 \%$ loss \\
\hline Unsatisfactory & Present & $<30$ loss & $>50 \%$ loss \\
\hline Failure & $\begin{array}{l}\text { Nonunion with or without } \\
\text { loss of motion }\end{array}$ & & \\
\hline
\end{tabular}

Table 2: Demographic and fracture pattern in two groups.

\begin{tabular}{|lll|}
\hline & Group LC-DCP ( 28 subjects) & Group LCP (26 subjects) \\
\hline Mean Age $\mathbf{S D}$ (years) & $34.7 \pm 13.4$ & $32.4 \pm 11.2$ \\
\hline Gender & & 19 \\
\hline Male & 21 & 07 \\
\hline Female & 07 & 14 \\
\hline Side & 17 & 12 \\
\hline Right & 11 & \\
\hline Left & & 17 \\
\hline Mode of Trauma & 17 & 09 \\
\hline High Energy & 11 & \\
\hline Low Energy & & 20 \\
\hline Type Of fracture & 21 & 06 \\
\hline Close fracture & 07 & 03 \\
\hline Open fracture & 04 & 03 \\
\hline Grade 1 & 03 & $4.9 \pm 2.2$ \\
\hline Grade 2 & $26.0 \pm 7.1$ \\
\hline Mean Preopreative Stay \pm SD (days) & $5.9 \pm 2.5$ & \\
\hline Mean follow up \pm SD (months) & $27.4 \pm 8.9$ & \\
\hline
\end{tabular}

Table 3: Fracture pattern based on AO classification.

\begin{tabular}{|llll|}
\hline AO type & LC-DCP & LCP & Total \\
\hline 22-A3.1 & 3 & 7 & 10 \\
\hline $\mathbf{2 2}-\mathbf{A 3 . 2}$ & 10 & 6 & 16 \\
\hline $\mathbf{2 2}-\mathbf{A 3 . 3}$ & 3 & 3 & 6 \\
\hline $\mathbf{2 2}-\mathbf{B 3 . 1}$ & 5 & 2 & 7 \\
\hline $\mathbf{2 2 - B 3 . 2}$ & 4 & 3 & 7 \\
\hline $\mathbf{2 2}-\mathbf{B 3 . 3}$ & 2 & 4 & 6 \\
\hline $\mathbf{2 2}-\mathbf{C 3 . 1}$ & 1 & 1 & 2 \\
\hline
\end{tabular}

Table 4: Mean duration of surgery and time to union in two groups.

\begin{tabular}{|llll|}
\hline & Group LC-DCP & Group LCP & P value \\
\hline Mean duration of surgery & $88.6 \pm 15.0$ & $80.8 \pm 15.7$ & 0.062 \\
\hline Mean time to union & $17.7 \pm 8.6$ & $16.0 \pm 5.8$ & 0.397 \\
\hline
\end{tabular}

Table 5: Anatomical and Non-anatomical reductions in each group.

\begin{tabular}{|llll|}
\hline & Group LC-DCP(n=28) & Group LCP $(\mathbf{n = 2 6})$ & P value \\
\hline Anatomic reduction & 20 & 12 & 0.095 \\
\hline Non anatomic reduction & 08 & 14 & 0.095 \\
\hline
\end{tabular}

Table 6: Functional outcome.

\begin{tabular}{|ll|lll|}
\hline Group & Excellent & Satisfactory & Unsatisfactory & Failure \\
\hline LC-DCP $(\mathbf{n = 2 8})$ & 16 & 9 & 2 & 1 \\
\hline LCP $(\mathbf{n = 2 6})$ & 20 & 5 & 1 & 0 \\
\hline
\end{tabular}


Table 7: Mean ROM and DASH score in each group.

\begin{tabular}{|llll|}
\hline ROM & LC-DCP $(\mathbf{n}=\mathbf{2 8})$ & LCP $(\mathbf{n}=\mathbf{2 6})$ & P value \\
\hline Elbow flexion & & & 0.649 \\
\hline Wrist flexion & $136.8^{\circ} \pm 11.3$ & $138.1^{\circ} \pm 9.2$ & 0.187 \\
\hline Pronation supination & $138.9^{\circ} \pm 9.4$ & $141.9^{\circ} \pm 6.8$ & 0.171 \\
\hline DASH score & $137.9^{\circ} \pm 17.7$ & $143.8^{\circ} \pm 13.6$ & 0.718 \\
\hline
\end{tabular}

AO ASIF classification was utilized to classify them and number of patients in each subgroup is depicted in Table 3.

Group LC-DCP was composed of 28 patients (19 males and 7 Females; mean age $34.7 \pm 13.4)$. Group LCP comprised 26 patients (19 males and 7 females; mean age $32.4 \pm 11.2$ ). Mean time to surgery was $5.9 \pm 2.5$ (range 2-12) days in group LC-DCP and $4.9 \pm 2.2$ (range 2-11) days in group LCP.

Mechanism of injury was high energy impact in $60.7 \%$ in LC-DCP group and $65.4 \%$ in LCP group and low energy injury in $39.3 \%$ in LC-DCP group and $34.6 \%$ in LCP group. Average follow up was $27.4 \pm 8.9$ months in group LC-DCP (range 18 to 52 months) and $26.0 \pm 7.1$ months in group LCP (range 18 to 43 months).

The mean time required for LC-DCP fixation (88.6 \pm $15.0 \mathrm{~min})$ was calculated to be more than that for LCP fixation $(80.8 \pm 15.7 \mathrm{~min})$ although the difference was statistically insignificant $(\mathrm{p}=.062)$ in Table 4.

\section{Union}

Mean time to bony union was also insignificantly more in LC-DCP group $(17.7 \pm 8.6)$ as compared to LCP group. $(16.0 \pm 5.8)$ (Table 4) Fractures united in all patients except one in LCDCP group who had loosening of both plates secondary to a deep infection and underwent implant removal, debridement and refixation with longer LCPs and subsequently united 1 year after the index procedure. Delayed union was discerned in 2 patients in LC-DCP group and 1 in LCP group. All had an uneventful union without resorting to any secondary procedure. Deep infection developed in 1 patient in each group. One with LC-DCP had nonunion as detailed above whole the one with LCP underwent into delayed union and had implants removed at 9 months. Superficial infection was recognized in 1 patient in LC-DCP group and 2 in LCP group .All were tackled conservatively with $3^{\text {rd }}$ generation cephalosporin antibiotics.

Patients were also segregated into two subgroups in both the group on the basis of weather anatomic reduction could be attained or not and the compared on the grounds of the amount of callus formation within each subgroup which was assessed using the criteria of Leung et al. ${ }^{5} \mathrm{We}$ could achieve anatomic reduction in $20(71 \%)$ of fractures in LC-DCP group and $12(46 \%)$ of fractures in
LCP group ( $\mathrm{p}=0.095)$ (Table 5), in the remaining cases reduction was nonanatomic. Expressing in terms of callus formation, in the LC-DCP group, $86 \% \quad(n=24)$ of forearms had no radiological evidence of callus formation, $7 \% \quad(n=2)$ had minimal callus, $7 \% \quad(n=2)$ revealed moderate callus while none had abundant callus. In the LCP group, $62 \%(n=16)$ of the forearms healed with callus formation of which $16 \%(n=4)$ displayed abundant callus formation, $27 \%(n=7)$ showed moderate callus, $19 \%(n=5)$ revealed minimal callus and the rest $38 \%(\mathrm{n}=10)$ experienced no callus formation. In Figure 1, the results were discovered to be statistically significant. ( $\mathrm{P}=0.003$, Fischer's study exact test $)$ when compared with respect to the number of forearms that healed with abundant or moderate callus and those that healed with minimal or no callus radiologically.

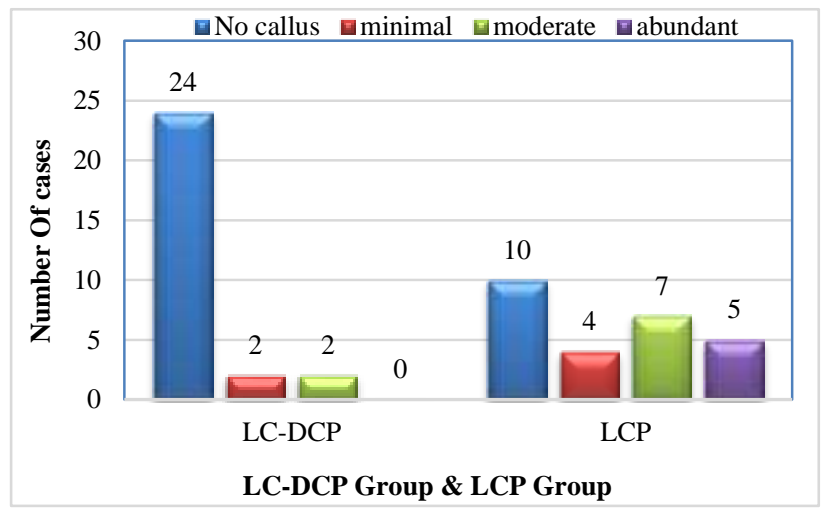

Figure 8: The graphic representation of callus formation in two groups.

None of the $20(0 \%)$ anatomically reduced forearms fixed with LCDCP had any evidence of callus formation while two of the $12(17 \%)$ anatomically reduced forearms fixed with LCP displayed callus formation. Of the nonanatomically reduced forearms, 4 out of 8 forearms $(50 \%)$ of those fixed with LCDCP exhibited evidence of callus and all the 14 forearms $(100 \%)$ in the LCP group unveiled evidence of callus. The difference between the cases that had been reduced anatomically and nonanatomically, with respect to the presence of callus, was recorded to be quite significant in both the LC-DCP and the LCP groups ( $\mathrm{p}=0.003$ and 0.000 , respectively).

The mean ranges of elbow, wrist joint and pronationsupination movements in the LC-DCP group were $136.8^{\circ}$, $138.9^{\circ}$ and $137.9^{\circ}$, respectively, while they were $138.1^{\circ}$, $141.9^{\circ}$ and $143.8^{\circ}$, respectively, for the LCP group. No 
significant differences could be established with respect to these range of movements $(\mathrm{P}=0.649,0.187$ and 0.171 respectively).

According to the Andersons' criteria, in the LC-DCP group, 16 patients had excellent results, 9 patients had satisfactory, and 2 patients had unsatisfactory results and 1 was recognized as failure. In the LCP group, 20 patients had excellent results, 5 patients had satisfactory and 1 patient had unsatisfactory results and none had failure. In Table 6, Mean DASH score was $20.6 \pm 12.9$ (range 058.3 ) in the LC-DCP group and $19.4 \pm 12.6$ (range 050.1 ) in the LCP group. No significant difference existed between the 2 groups in terms of Andersons' criteria and DASH scores in Table 7.

Temporary radial nerve palsy was detected in 2 patients in LC-DCP group which improved conservatively by $12^{\text {th }}$ week. One patient in LCP group had permanent radial nerve palsy that necessitated tendon transfer surgery after 1 year. In all cases the fractures involved proximal thirds of both bones. We did not document any case of refracture or synostosis in our series.

\section{DISCUSSION}

Literature acknowledges open reduction and internal fixation as the standard management of fractures involving both bones of the forearm. ${ }^{5}$ In the past, DCPs have been endorsed as the foremost implant for these fractures but with the advent of newer implant, this has become a matter of argument. ${ }^{15}$ The latest edition to the armory of orthopaedic surgeons, the Locked plates act as a perfectly implanted external fixator and present a novel bio friendly approach to internal fixation. ${ }^{13}$ Unperturbed bone perfusion reduces infection rate, bone resorption, delayed and nonunion. Currently established indications for their use include complex periarticular and intra articular fractures, osteotomies, periprosthetic fractures, failed fixations, union disturbances, osteoporosis etc. ${ }^{16,17}$ Though a few studies assert their superiority over the conventional plating, evidence in literature is still scant. ${ }^{18-}$ 20

Analogous biomechanical properties of LCPs and DCPs have been delineated in a radius cadaver model by Gardner et al. ${ }^{21}$ However, Snow et al, in a biomechanical study of an osteoporotic bone model discovered the LCPs to perform better in the axial compression test when used as a bridge plate against the conventional plates. ${ }^{22}$ Furthermore, Doornink et al validated that hybrid plates impart higher torsional strength, similar bending strength, and a minimal decrease in axial strength than all locked plates in a biomechanical study of an osteoporotic diaphyseal fracture model. ${ }^{23}$ In spite of these experimental studies confirming the lead of LCPs over DCPs and all locked plates, clinical trials have failed to reestablish this in forearm fractures. ${ }^{24-26}$
In our series, we disclosed one incident of nonunion in LC-DCP group with equivalent mean time to union between the groups ( $p=0.397$ ). 100\% union rates have been claimed by Leung et al in their randomized control trial (RCT) comparing LC-DCP with PC-Fix with an average union period of 17 and 18 weeks, respectively for closed fractures. ${ }^{9}$ More recently, Saika et al too have reported $100 \%$ union rates with mean time to union lesser with LCP than LC-DCP. ${ }^{24}$ Matching observations were published by Azboy et al using DCP in place of LC$\mathrm{DCP}^{25}$ On the contrary, Stevens et al proclaimed mean consolidation time favoring DCP over LCP. ${ }^{26}$ Likewise, in a recent study by Reddy et al, it was documented to be more in LCP than LC-DCP. ${ }^{27}$

Compression techniques have been proved to reduce union time regardless of the implant. Stevens et al revealed that the time to union was an average of 10 weeks less when compression was applied in both groups (DCP and LCP). ${ }^{26}$ The authors propounded that it is the axial compression applied to the fracture line which dictates the time to union rather than the type of plate. A lower incidence of nonunion with faster rehabilitation and less joint stiffness too have been acclaimed. ${ }^{28,29}$

In our research, the number of patients that had anatomic reduction with LC-DCP was greater than that with LCP as biological fixation with bridge plating was emphasized with LCP and consequently more callus was discerned with LCPs with either anatomic or non-anatomic reductions. This certainly underlines the biological nature of LCP plating. Either implant was applied without any compression in non-anatomic reduction or comminuted fractures in a bridging mode (LCP) or conventional mode (LC-DCP) without compression. Wagner accentuated the fact that LP is in fact an internal fixator that allows but does not obligates precise anatomic reduction and can be applied through an open but less invasive approach. ${ }^{30}$ It aims at flexible elastic fixation to initiate spontaneous healing including its induction of callus formation and thus complements bone biology. Leung too proclaimed that with LCP the quality of reduction and stability control decide the type and speed of healing. ${ }^{5}$ Egol et al also remarked that in a fractures with a wider gap and strain $<10 \%$, locked plates pretend to be an internal fixator contributing ample stability favoring secondary bone healing through enchondral ossification. ${ }^{10}$

We described 1 case of deep infection in each of the group. The one with LC-DCP had loosening of both plates and underwent revision plating with LCP while the one with LCP only had delayed union without implant loosening. Though the number of cases was too less to draw any conclusion but it can be postulated that in the face of adversities such as infection or cortical porosis, the strength of locking screw plate construct may counteract any loosening of screws. As asserted by Egol et al the plate with locked screws forms a mono block construct that rely less on the quality of bone and anatomic anchoring region. ${ }^{10}$ The substitute cortex 
afforded by LCP impartially distributes deforming loads to all the screws in contrast to those closest and farthest from the fractures site with conventional plating.

The comparatively less mean duration of surgery with LCP identified in our study, although statistically insignificant, could be accredited to a supplementary step of tapping the screw holes that a conventional screw demands. This was in sharp contradiction to Saikia and Haribabu et al who recorded it to be more with LCP although insignificantly. ${ }^{24,31}$

No significant differences could be brought about between the group with regard to functional aspects in spite of exercising on three different criteria (ROM: elbow and wrist flexion and forearm pronation and supination; Andersons criteria and DASH score). Many precedent studies too have echoed our findings. ${ }^{5,6,24-27}$

Implant removal was taken up in overall 18 patients $(10$ in LC-DCP group and 8 in LCP group) mostly on patients' request who had hardware prominence or uneasiness. However, it could not be accomplished in two patients with LCP due to cold fusion between the screws and plate. Hand tightening of locking screws as advocated by Henle et al is recommended. ${ }^{32}$ They also published one refracture during removal of ulnar locking plate. No complexities were confronted in LC-DCP group. Special devices for screw removal must always be kept at bay and patient cautioned that implant removal may not always be feasible.

No incident of refracture was encountered by us. Accomplishing implant removal after 18 months of surgery and supplementing with above elbow splint as a rule for 3 weeks appears attributable. Leung it all recorded $9 \%$ refracture rate at original fractures site in his series with LCP when implants were removed by 12 months and he advocated the pertinent time to do so is after 18 months. He had also published one incident of refracture with both in his RCT comparing LC-DCP and PC Fix. A range varying from 4 to $25 \%$ has been reported by many precedent studies. $6,28,33,34$.

Our study being a prospective enabled us to study better the outcome of specific parameters and to draw comparisons eliminating bias at the same time but limited number of patients made it worthless to analyze the efficacy of implants in different subgroups of $\mathrm{AO}$ classification. A RCT preferably a triple blind or at least double blind in nature with ample number of patients and prolonged follow up is desired to draw out significant differences.

To close, LCP is reliable to achieve union even in patients belonging to younger age group with higher activity level in fractures of both bones of forearm. Although the current study could not document its ascendancy over LC-DCP, it can be advertised as an implant of choice as a bridging device in managing comminuted fractures and failed LC-DCP fixations. Almost triple implant cost in comparison to LC-DCP makes routine use unjustifiable. We conceive that surgical techniques and proper applications of principles of plating rather than the type of implant are more crucial for optimal results.

\section{Funding: No funding sources Conflict of interest: None declared \\ Ethical approval: The study was approved by the institutional ethics committee}

\section{REFERENCES}

1. Chow SP, Leung F. Radial and ulnar shaft fractures. In: Bcholz RW, Charles MC, James DH, Paul T, editors. Rockwood and Green's Fractures in adult. $7^{\text {th }}$ ed. Lippincott. Robert WB, Williams \& Wilkins; 2010: 882-893.

2. Andrew 11, Crenshaw Jr, Edward A. Perez. Fractures of Shoulder, arm, and forearm. In: Canale ST, Beaty JH, editors. Campbell's operative orthopaedics. 11thedition: Mosby; 2008: 34253433.

3. Aljo Matej E, Lvica M, Tomljenocie M, Krolo 1. Forearm shaft fractures: result of 10 year follow up. Acts Clin Croat. 2000;39(3):147-53.

4. Knight RA, Purvis GD. Fractures of both bone forearm in Adults. J Bone Joint Surg Am. 1949;31:755-64.

5. Leung F, Chow SP. Locking compression plate in the treatment of forearm fractures: A prospective study. J Orthop Surg (Hong Kong). 2006;14:291-4.

6. Anderson LD, Sisk D, Tooms RE, Park WI., 3rd Compression-plate fixation in acute diaphyseal fractures of the radius and the ulna. J Bone Joint Surg Am. 1975;57:287-7.

7. Bagby GW, James JM. The effect of compression on the rate of Fracture healing using a special plate. Am J Surg. 1958;95:761-71.

8. Müller ME, Allgöwer M, Willenegger H. Technique of internal fixation of fractures. NewYork: Springer; 1965.

9. Leung F, Chow SP. A prospective, randomized trial comparing the limited dynamic compression plate with the point contact fixation for forearm fractures. J Bone Joint Surg Am. 2003;85:2343-8.

10. Egol KA, Kubiak EN, Fulkerson E, Kummer FJ, Koval KJ. Biomechanics of locked screws and screws. J Orthop Trauma. 2004;18:488-3.

11. Broos PL, Sermon A. From unstable internal fixation to biological osteosynthesis.A historical overview of operative fracture treatment. Acta Chir Belg. 2004;104:396-400.

12. Perren SM, Klaue K, Pohler O, Predieri M, Steinemann S, Gautier E. The limited contact dynamic compression plate (LC-DCP). Arch Orthop Trauma Surg. 1990;109(6):304-10.

13. Frigg R. Locking compression plate (LCP): an osteosynthesis plate based on the dynamic compression plate and the Point Contact Fixator (PC-Fix). Injury. 2001;32(2):63-6. 
14. Hudak PL, Amadio PC, Bombardier C. Development of an upper extremity outcome measure: the DASH (disabilities of the arm, shoulder and hand) [corrected]. The Upper Extremity Collaborative Group (UECG). Am J Ind Med. 1996;29(6):602-8.

15. Rao MR, Kader E, Sujith S, Thomas V, editors. Nail plate combination in management of fracture both bone forearm. Orthop Proceedings. 2002;84(3):2523.

16. Sommer C, Gautier E, Müller M, Helfet DL, Wagner M. First Clinical results of the locking compression plate. Injury. 2003;34:43-54.

17. Ling HT, Kwan MK, Chua YP, Deepak AS, Ahmad TS. Locking compression plate: A treatment option for diaphyseal nonunion of radius or ulna. Med $\mathbf{J}$ Malaysia. 2006;61:8-12.

18. Haidukewych GJ. Innovations in locking plate technology. J Am Acad Orthop Surg. 2004;12:20512.

19. Dickson KF, Munz J. Locked plating: Clinical indications. Tech Orthop. 2007;22:181-5.

20. Atsunori S, Genzaburo N, Tsukasa I, Naoya T. Treatment of forearm fractures using locking compression plate (LCP, AO/ASIF) Orthop Surg Traumatol. 2004;47:1293-8.

21. Gardner MJ, Brophy RH, Campbell D, Mahajan A, Wright TM, Helfet DL, et al. The mechanical behavior of locking compression plates compared with dynamic compression plates in a cadaver radius model. J Orthop Trauma. 2005;19(9):597603.

22. Snow M, Thompson G, Turner PG. A mechanical comparison of the locking compression plate (LCP) and the low contact-dynamic compression plate (DCP) in an osteoporotic bone model. J Orthop Trauma. 2008;22(2):121-5.

23. Doornink J, Fitzpatrick DC, Boldhaus S, Madey SM, Bottlang M. Effects of hybrid plating with locked and nonlocked screws on the strength of locked plating constructs in the osteoporotic diaphysis. J Trauma. 2010;69(2):411-7.

24. Saikia KC, Bhuyan SK, Bhattacharya TD, Borgohain M. Internal fixation of fractures of both bones forearm: Comparison of locked compression and limited contact dynamic compression plate. Indian J Orthop. 2011;45(5):417-21.
25. Azboy I, Demirtas A, Uçar BY, Bulut M, Alemdar C, Ozkul E. Effectiveness of Locking Versus Dynamic Compression Plates for Diaphyseal Forearm Fractures. Orthopedics. 2013;36(7):917-22.

26. Stevens CT, Ten Duis HJ. Plate osteosynthesis of simple forearm fractures: LCP versus DC plates. Acta Orthop Belg. 2008;74:180-3.

27. Reddy BJ, Abhishek L, Kathyayini R. Comparative study of forearm fractures treated with locking compression plate or limited contact dynamic compression plate. J Evol Med Dental Sci. 2015;4(12):2001-10.

28. Chapman MW, Gorden JE, Zissimos AG. Compression plate fixation of acute fractures of the diaphyses of the radius and ulna. J Bone Joint Surg Am. 1989;71:159-69.

29. Goldfarb CA, Ricci WM, Tull F, Ray D, Borelli J., Jr. Functional outcome after fracture of both bones of the forearm. J Bone Joint Surg Br. 2005;87:3749.

30. Wagner $\mathrm{M}$. The general principles for the clinical use of LCP. Injury. 2003;34:31-42.

31. Hari Babu S, Rajesh M, Suresh Babu G, Anand L. Comparative study of dynamic compression plate versus locking compression plate in the management of diaphyseal fracture of both bones forearm. J Evidence Based Med Healthcare. 2015;2(40):6717-24.

32. Henle P, Ortlieb K, Kuminack K, Mueller CA, Suedkamp NP. Problems of bridging plate fixation for the treatment of forearm shaft fractures with the locking compres $\neg$ sion plate. Arch Orthop Trauma Surg. 2011;131(1):85-91.

33. Hidaka S, Gustilo RB. Refracture of bones of the forearm after plate removal. J Bone Joint Surg Am. 1984;66:1241-3.

34. Deluca PA, Lindsey RW, Ruwe PA. Refracture of bones of the forearm after the removal of compression plate. J Bone Joint Surg Am. 1988;70:1372-6.

Cite this article as: Gill SPS, Mittal A, Raj M, Singh P, Kumar S, Kumar D. Stabilisation of diaphyseal fractures of both bones forearm with limited contact dynamic compression or locked compression plate: comparison of clinical outcomes. Int J Res Orthop 2017;3:623-31. 